\title{
Infection, nutrition and growth in a rural African environment
}

\author{
By R. G. Whitehead, M. G. M. Rowland and T. J. Cole, Dunn Nutritional \\ Laboratory, University of Cambridge and Medical Research Council, \\ Milton Road, Cambridge $\mathrm{CB}_{4} \mathrm{IXY}$
}

A dietary deficiency in any essential nutrient can curtail growth. This has been studied extensively in laboratory and farm animals, as well as in man. The fact that infection can also cause growth faltering is equally well known.

If a person is both malnourished and suffering from an infection one would expect the over-all effect on growth to be considerable. For the purposes of this symposium we will be concentrating on the typical growth pattern seen among many young children in the developing countries when they are subjected to deficiencies of dietary energy and protein in association with frequent concomitant infection. Most of the results presented come from personal experiences in two African village communities, one in Uganda, the other in The Gambia.

\section{Nutritional anthropometry}

In the developing countries anthropometry is the principal means used to assess nutritional status. Most nutritionists have come to accept that weight gives the most significant information if it can be measured serially as, for example, in a children's under 5 clinic. When this is not possible, as in cross-sectional surveys, it has been recommended that weight should be expressed as a percentage of the 'expected' weight for a normal child of that age. The standard weight tables most frequently used have been those compiled by Jelliffe (1966). When it has proved impossible to run to the luxury of weighing scales, perhaps during an emergency situation, alternative measurements have included the mid-upper arm circumference. This and other techniques are described in detail by Jelliffe (1966).

Height has usually been regarded as a less sensitive measure of malnutrition, mainly because it is impossible to lose height as one can weight. This, and probably the difficulty of measuring height accurately with the tools normally available to nutritionists, led Hiernaux ( 1963 ) to the view that height was relatively 'nurture insensitive'. More recently this view has been challenged and the significance of height as a measure of malnutrition has been critically reviewed by Waterlow (1972, 1973), who has recommended that height retardation should be looked upon as an indication of long-term malnutrition as opposed to a low weight, which, if in the presence of a more normal height, might indicate recent acute malnutrition. 
The danger has been that nutritional survey teams have been too ready to assume that growth retardation and wasting are sufficient proof in themselves to establish the existence of primary dietary deficiency. While an increased food intake is essential for the treatment and rehabilitation of such children, dietary intervention might not be the best way to prevent the wasting. Obviously if some other environmental factor is operating, it might be more beneficial to focus one's main attention on this problem initially rather than on the diet per se.

\section{Growth and infection}

Although wasting associated with illness and infection has always been recognized, it was only surprisingly recently that the link between both diet and infection to the development of protein-energy malnutrition has become widely accepted. I suppose the probable explanation for this reluctance to accept what in retrospect should have been obvious, lies in the historical controversies surrounding the disease, particularly kwashiorkor. In East Africa certainly, the fight to convince the medical profession that kwashiorkor was a dietary disease and was not the direct result of an infection had been a hard one. No doubt it was for this reason that Trowell, Davies \& Dean (1954) in their classical treatise on kwashiorkor were so unrelentingly definite when they said 'Even the most careful history taking has failed to provide any trustworthy evidence for the relationship between an infection and the onset of kwashiorkor'.

The work which did most to establish the inseparable link between nutritional status of infants and young children and the pattern of infection they had been subjected to was the work of Mata, Urrutia \& Gordon (1967), who demonstrated by prospective longitudinal studies among children in Guatemala that weight faltering was, more often than not, closely associated with the pattern of infection. Seemingly a wide range of infections could be involved. Similar results were forthcoming from The Gambia (McGregor, Rahman, Thomson, Billewicz \& Thompson, 1970), and from Uganda (Frood Whitehead \& Coward, 1971). A typical example from the latter country is shown in Fig. I, which shows not only the weight chart of the child but also what happened to plasma albumin concentrations following two successive bouts of infections. This and similar results from other individuals were important because they showed that not only could infection be closely related to wasting and consequently the development of marasmus, it could also result in a fall in serum albumin concentrations and thus make children prone to oedema and hence kwashiorkor.

It was results like these that helped to define one of the current views of proteinenergy malnutrition as not just a dietary disease, but more generally as part of a tropical 'failure to thrive' syndrome. The main difference between this and what is usually meant by failure to thrive in the UK is that in the latter situation there is often one predominating chronic abnormality, while in a developing country it is more frequently the case that a rapid succession of infections and other environmental hazards cause the growth retardation. 


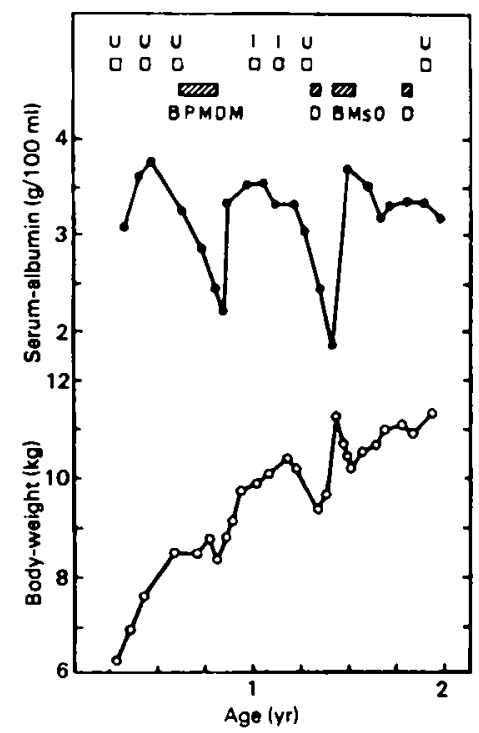

Fig. I. Relationship between pattern of infection, weight faltering and episodes of hypoalbuminaemia in a Ugandan child (Frood et al. 1971). U, upper-respiratory-tract infection; I, impetigo; B, bronchitis; $P$, pneumonia; $M$, malaria; $D$, diarrhoea; $M$, measles; $O$, otitis media.

\section{The quantitative relationship between growth and individual infection}

Once one accepts that protein-energy malnutrition can be just as much the product of infection as dietary deficiency, it becomes obvious that the applied nutritionist concerned with the prevention of protein-energy malnutrition needs to collaborate within a wider public health framework. Not only is it important to define and quantify the actual nutrients which are deficient, it is also necessary to quantify the contribution of different infections to the malnutrition. There is need to quantify the effect of other environmental factors, of course, but they are not the subject of this talk. This will need to be done for each affected area as geographical differences are inevitable. Such time-consuming work is essential, however, otherwise there is a grave risk of a child health intervention programme being too non-specific to get at the root cause of the problem.

A recent attempt to quantify the relationship between acute morbidity and physical growth of rural Guatemalan children has been published by Martorell, Habicht, Yarbrough, Lochtig, Klein \& Western (1975). This was a study on 716 children ranging in age from 15 days to 7 years and the growth variables investigated were semestral (6 monthly) and yearly increments in body-length and weight. The diseases quantified were diarrhoea, fevers and respiratory tract infections and the number of days the child presented with these symptoms was used as the measure of morbidity. The rather surprising result, in view of the earlier findings of Mata et al. (1967), was that fevers and respiratory tract infections appeared to have no significant effect on growth. The situation with diarrhoea, however, was quite different. Children less ill with diarrhoea showed 
substantially larger increments in length and weight than children who were ill with diarrhoea a greater percentage of the time. The authors concluded that their findings highlighted that diarrhoea was the major public health problem associated with the development of growth faltering in their country.

Similar conclusions implicating diarrhoea as one of the main problems might be inferred from the qualitative work of earlier investigators (Marsden, 1964; Morley, Bicknell \& Woodland, 1968) working in Africa, and this has been recently substantiated in a study carried out in a rural village called Keneba, in The Gambia (Rowland, Cole \& Whitehead, 1977). Estimates of incremental gains in weight and length were calculated from measurements made routinely every month. The interval between one anthropometric measurement and the next was then searched for bouts of illness. The duration of each illness was then used to determine the proportion of time the child was being affected by that particular illness.

The relationship between height and weight gain and the duration of each of nine disease categories was then investigated by multiple regression analysis. For height gain only diarrhoeal disease had a significant negative correlation. With weight gain gastroenteritis was again a predominant factor, but malaria was also significant. The remaining disease groupings made a statistically insignificant contribution.

An attempt has been made to calculate what might have happened to the growth rates of these children if we could eliminate the diarrhoea; this is illustrated in Fig. 2. Because of known seasonal variations in growth the study period has been divided into two-monthly segments. The point where each regression line cuts the growth axis represents the mean growth rate that would have occurred had there been no gastroenteritis.

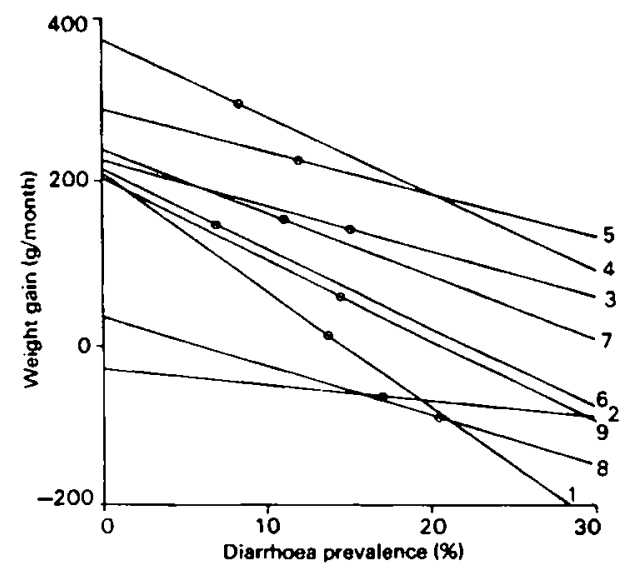

Fig. 2. Fitted regression lines of weight gain on diarrhoea prevalence in Keneba, The Gambia, for nine 2-month periods, from May 1974 to October 1975 (Rowland et al. 1977). 1. May-June 1974; 2. July-August 1974; 3. September-October 1974; 4. November-December 1974; 5. January-February 1975; 6. March-April 1975; 7. May-June 1975; 8. July-August I975; 9. September-October 1975. 
Except during the months of July and August, both in 1974 and 1975, rates of growth would have averaged between 200 and $25^{\circ} \mathrm{g} /$ month. Mean growth rates of standard children between 0.5 and 3.0 years, the age range covered in our study, vary from $57^{\circ-1} 10 \mathrm{~g} /$ month, and thus, except in the youngest infants, the elimination of diarrhoea would theoretically enable virtually normal rates of growth to occur, and, indeed, in older children some degree of catch-up. The exceptions, July and August, are part of the traditional hungry season when the previous year's cereal crop has been used up and the new harvest is not yet ready. For Gambian children in their and and 3rd years of life this would appear to be the only time of the year when diet rather than gastroenteritis could be the predominating factor in the development of a marasmic condition.

\section{Physiological factors responsible for the inhibition of growth by infection}

Diet. What are the factors responsible for the close interaction between infection and nutritional status, as measured by growth? In the case of diarrhoea an important component is immediately obvious. Clearly, nutrients which are lost almost as soon as they are consumed can be of little metabolic benefit. The cells of the body are being just as effectively deprived of nutrients as if the child were being starved.

Infections also affect appetite. Rarely does a child who is ill retain his normal desire for food particularly when this is of the bulky, stodgy variety so common in many developing countries. The influence on growth of a variety of infections on nutrient intake from a traditional Ugandan diet has been studied in a metabolic ward by Rutishauser \& Frood (1973). Although the intake of a milk-based diet could be maintained in children when they were ill this was not possible using the traditional diet even when the children were fed five times/d instead of the more customary two.

With other infections, for example fevers like malaria, the negative nitrogen balance associated with the pyrexia is sufficient to halt growth.

Hormonal changes. Infections also induce, within the child, hormonal changes which tend to inhibit growth. Lunn, Whitehead, Hay \& Baker (1973) have studied the switches in hormonal balance which occur in rural Ugandan children between when they were well and eating their high carbohydrate-containing food and when they were ill with some infections. Plasma insulin concentrations which were originally high became reduced and cortisol concentrations became correspondingly high.

The relationship between growth and the concentrations of plasma cortisol and insulin have been studied in greater depth as part of our present prospective longitudinal study in The Gambia and the results are summarized in Fig. 3. The negative correlation between growth and cortisol $(\Gamma=-0.4 \mathrm{I} ; P<0.001)$ and the even stronger positive one with insulin $(\Gamma=+0.51 ; P<0.001)$ confirm the impressions gained from our Uganda studies.

The physiological reasons for these hormonal changes are complex and in themselves illustrate the close interaction between diet and disease. As already 

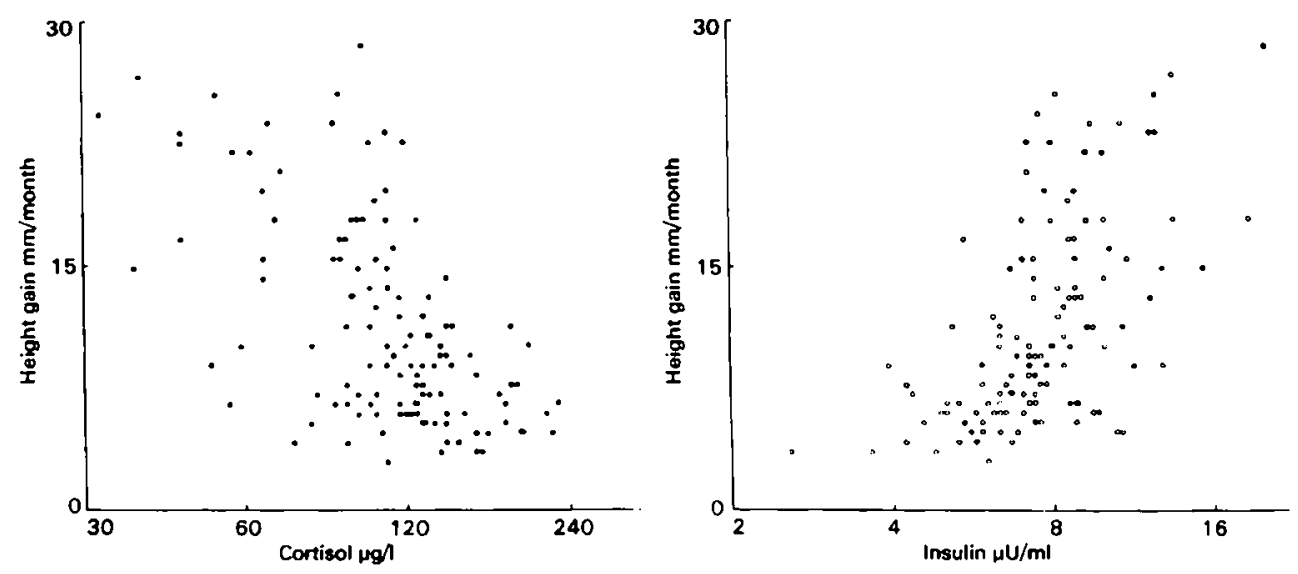

Fig. 3. Relationship between plasms insulin and cortisol concentrations and growth in height of children in the village of Keneba, The Gambia.

indicated, the stress of infection can result in an increase in cortisol and the close relationship between the severity of different infections and the magnitude of associated plasma cortisol concentrations has been emphasized by Lunn et al. (1973). In rats, however, nutrient deprivation alone can also produce elevated corticosterone levels (Coward, Whitehead \& Lunn, 1977).

In view of the central role in metabolism played by insulin and cortisol it is not surprising that there is a strong relationship between their plasma levels and major changes in growth pattern. The elevated cortisol levels are no doubt induced partially by the need for gluconeogenesis. Indeed, Alleyne \& Young (1967) were able to demonstrate a good correlation between cortisol and fasting blood glucose concentrations.

Once elevated in concentration, cortisol has a pronounced anti-anabolic effect on protein synthesis, but since it also stimulates the movement of free amino acids away from the more peripheral tissues to the internal organs like the liver, growth of muscle and connective tissues is preferentially inhibited, especially when dietary protein intake is only marginally sufficient to cover requirements. The role of corticosteroids in altering the distribution of amino acids between liver and muscle in rats fed low protein-containing diets has recently been studied by Lunn, Whitehead, Baker \& Austin (1976).

Insulin has a completely opposite effect on amino acid distribution and protein synthesis and this is presumably the explanation for the positive correlations between plasma insulin concentration and growth in length.

This paper has concentrated primarily on the interaction between infection and malnutrition on growth, but of course other functions of the body are affected, in particular the various immune defence mechanisms against disease. It has been postulated, for example, that the high cortisol concentrations present in the plasma of malnourished children may inhibit leucocyte transformation. In this way a complex vicious cycle can develop, the greater the degree of infection the greater is 
the dietary deprivation which occurs, which in turn can inhibit the immune response.

Where and how one intervenes in such a complex situation depends on individual circumstances, but the need for nutritionists to concern themselves more widely in the public health services is obvious.

\section{REFERENCES}

Alleyne, G. A. O. \& Young, V. H. (1967). Clin. Sci. 33, 189.

Coward, W. A., Whitehead, R. G. 8 Lunn, P. G. (1977). Br. F. Nutr. In the press.

Frood, J. D. L., Whitehead, R. G. \& Coward, W. A. (1971). Lancet ii, 1047.

Hiernaux, J. (1963). Am. F. Phys. Anthrop. 21, 575.

Jelliffe, D. B. (1966). Wld. Hlth. Org. Monogr. Ser. 53.

Lunn, P. G., Whitehead, R. G., Hay, R. W. \& Baker, B. A. (1973). Br. Y. Nutr. 29, 399.

Lunn, P. G., Whitehead, R. G., Baker, B. A. \& Austin, S. (1976). Br. F. Nutr. 36, 537.

McGregor, I. A., Rahman, A. K., Thomson, A. M., Billewicz, W. Z. \& Thompson, B. (1970). Trans. Roy. Soc. trop. Med. Hyg. 64, 48 .

Marsden, P. D. (1964). Trans. Roy. Soc. trop. Med. Hyg. 58, 455.

Martorell, R., Habicht, J. P., Yarbrough, C., Lochtig, A., Klein, R. E. \& Western, K. A. (1975). Am. $\mathcal{F}$. dis. Childh. 129, 1296.

Mata, L. J., Urrutia, J. J. \& Gordon, J. E. (1967). Trop. geogr. Med. 19, 247.

Morley, D. C., Bicknell, J. \& Woodland, M. (Ig68). Trans. Roy. Soc. trop. Med. Hyg. 62, 164.

Rowland, M. G. M., Cole, T. J. \& Whitehead, R. G. (1977). Br. F. Nutr. 37. In the press.

Rutishauser, I. H. E. \& Frood, J. D. L. (1973). Br. F. Nutr. 29, 26 r.

Trowell, H. C., Davies, J. N. P. \& Dean, R. F. A. (1954). In Kwashiorkor. London: Edward Arnold.

Waterlow, J. C. (1972). Br. med. Y. iii, 566.

Waterlow, J. C. (1973). Lancet ii, 87. 